\title{
Dynamic analysis of a lean cell under uncertainty
}

\author{
Ahmed M. Deif* \\ Industrial and Service Engineering Department, Nile University, Cairo, Egypt
}

\begin{abstract}
One of the ultimate targets of lean manufacturing paradigm is to balance production and produce at takt time in production cells. This paper investigates the performance of a lean cell that implements the previous lean goals under uncertainty. The investigation is based on a system dynamics approach to model a dynamic lean cell. Backlog is used as a performance metric that reflects the cell's responsiveness. The cell performance is compared under certain and uncertain external (demand) and internal (machine availability) conditions. Results showed that although lean cell is expected to be responsive to external demand with minimum waste, however, this was not the case under the considered uncertain conditions. The paper proposes an approach to mitigate this problem through employing dynamic capacity policy. Furthermore, the paper explores the effect of the delay associated with the proposed capacity policies and how they affect the lean cell performance. Finally, various recommendations are presented to better manage the dynamics of lean manufacturing systems.
\end{abstract}

Keywords: uncertainty; system dynamics; lean manufacturing; level production

\section{Introduction}

World-class companies in all sectors are committing more and more to lean manufacturing philosophy. Based on a survey by Industry Week that was released in November 2007, nearly $70 \%$ of manufacturers in the United States have adopted lean manufacturing as an improvement strategy (Pay 2008). The Manufacturing Engineering magazine reports that lean manufacturing is the dominant force changing the face of manufacturing as we know it (Hogg 2009). The principles and tools of this manufacturing paradigm are mainly built over the success story of the Toyota Production System (TPS). Lean manufacturing provides a way to do more and more with less and less. Lean manufacturing achieves the previous objective through a group of methods and tools that eliminate waste in the manufacturing system and focus on the value added activities. In lean manufacturing, value can only be defined by the ultimate customer (Womack and Jones 2003). Sanchez and Nagi (2001) simply define lean as a collection of operational techniques focused on productive use of resources. Another definition that highlights the human and the variability aspects in lean manufacturing is proposed by Shah and Ward (2007) where they define lean manufacturing as an integrated socio-technical system whose main objective is to eliminate waste by concurrently reducing or minimising supplier, customer, and internal variability.

Lean culture is not exclusive to manufacturing enterprises; however, it is expanding to other sectors. Examples include implementing lean culture and tools to healthcare (Graban 2008), service industries (Tracy and Knight 2008), information technology (Middleton 2001), office environment (Tischler 2006), construction (Nahmens 2007) and non-profit organisations (Sampson 2004).

With all the previous merits of lean philosophy, the dynamics of manufacturing systems with lean implementation are still questionable. The dynamics of lean manufacturing are generally demonstrated under uncertainty. Uncertainty in manufacturing context is usually referred to unpredictable performance or lack of information. Manufacturing uncertainty can be classified into two types: internal (or endogenous) such as machine breakdowns and external (or exogenous) such as demand volatility.

This paper investigates the dynamics associated with applying some of the lean principles into a manufacturing cell. The investigation is based on a system dynamics approach to model a manufacturing cell and explore the impact implementing production levelling and pull policies on the cell performance. The rest of the paper is organised as follows. In Section 2 a brief explanation on the lean objective to eliminate overproduction through

*Email: deif@nileuniversity.edu.eg 


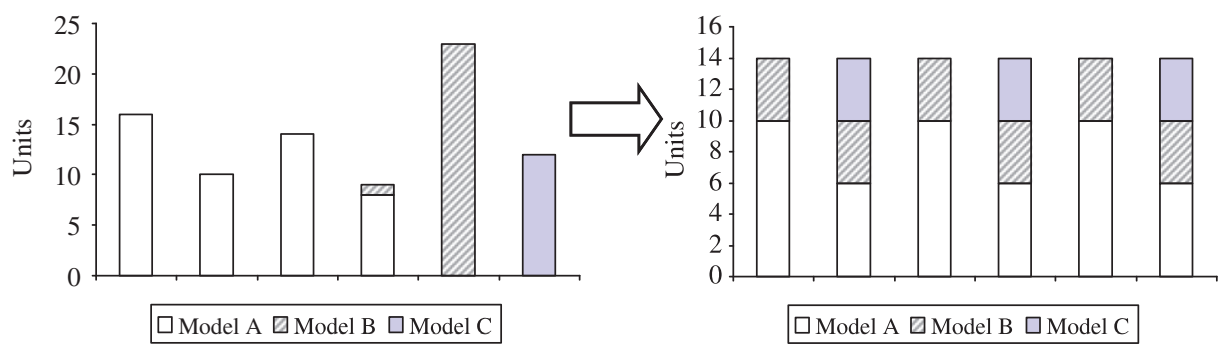

Figure 1. Level production in lean manufacturing systems.

production levelling and pull production policies. In Section 2 a review on analysing lean manufacturing systems is conducted. This is followed by presenting the dynamic cell manufacturing model in Section 4 . The model is extensively analysed in Section 5. Final conclusions and recommendations are presented in Section 6.

\section{Lean and overproduction}

The waste reduction philosophy of lean manufacturing looks at overproduction as a non-value added activity (waste) that should be eliminated. Unlike the classical mass production paradigm that employs 'batch-and-push' operation strategies, lean manufacturing efforts strive to eliminate overproduction resulting from these operation strategies. Overproduction means producing more, sooner or faster than is required by the next process (Rother and Shook 2003). The problems with overproduction are additional costs associated with handling, inspecting, counting and storing of these not yet needed products. In addition, with overproduction, defects remain hidden in the inventory queues until the downstream process finally uses the parts and discovers the problem (which by then is extensive and hard to trace). As a result, while the value creating time for producing one part is very short, the total time the product spends getting through the manufacturing system is too long.

Heijunka is the Japanese term for load or production levelling which is the lean manufacturing strategy employed to eliminate overproduction. The levelling here refers to both production volume as well as mix. Level production attains capacity balance and synchronisation of all production operations over time in a manner that precisely and flexibly matches customer demand for the system's products. In the ideal, this means producing every product every shift in quantities equal to demand (after smoothing out high frequency random components). Moreover, production cycle time should be less than the customer's acceptable waiting time for order receipt to enable demand-based scheduling.

To level production, processes should be operated at the takt time. The takt time is how often the manufacturer should produce one part based on the rate of sales to meet customer requirements; takt time synchronises the pace of production with the pace of sales. Producing at takt time is achieved through means such as rapid machine setups/changeover and flexible, multi-machine manning strategies. Small lot or, preferably, mixed-model sequenced production scheduling is employed. In addition, pull production operations should be implemented with its different Kanban system designs to maintain level production. Figure 1 explains the objective of the various lean approaches to achieve Heijunka or level production (volume and mix).

Although producing at takt time with level production should lead to continuous and smooth flow of production the dynamics of such a manufacturing setup are, however, still questionable. In other words, would these lean policies come with no expenses on the dynamics of the system? With the complex and uncertain environment in which manufacturing systems currently operate, the answer to the previous question requires more investigation. This paper is an initial attempt in this direction.

\section{Analysis of lean manufacturing in literature}

The details and description of the classical lean manufacturing system's philosophies and tools are well documented by some of the early researchers of the lean system (for example, Schonberger 1982, Hall 1983 and Shingo 1989). A recent review on lean manufacturing can be found in Shah and Ward (2007). 
Analytical approaches to study lean manufacturing systems include the work of Black (2007) who presented a group of qualitative and quantitative rules to implement lean manufacturing. The approach focused on how to change the current mass production operation of industries to a lean operation. Black presented nine different design rules for that transformation. Askin and Krishman (2009) proposed an approach based on queuing theory to investigate control points in a multi-stage lean manufacturing system. They investigated necessary and sufficient conditions for the optimality of a single control point as well as multiple control points. The impact of product mix and utilisation parameters on the number of control points was also explored the lean system they consider. Cochran et al. (2000) applied axiomatic design principles to design lean manufacturing systems with focus on line segmentation. They showed that integrating axiomatic design rules with lean management improved the design and performance of manufacturing systems. Hu et al. (2008) developed a decision support system based on multiobjective formulation to apply lean manufacturing concepts. The lean concepts were utilised to solve the project portfolio selection problem in manufacturing systems. Pavnaskar et al. (2003) developed a qualitative classification scheme for lean manufacturing tools which can help companies implementing the Lean and Six Sigma concepts. Detty and Yingling (2000) demonstrated the use of discrete event simulation as a tool to assist organisations with the decision to implement lean manufacturing by quantifying the benefits achieved from applying lean principles. Other simulation studies were also conducted to investigate the impact of just in time (JIT) and pull lean principles on improving manufacturing system performance (Carlson and Yao 1992, Galbraith and Standridge 1994, Welgoma and Mills 1995, Savasar and Al-Jaini 1995). Lian and Van Landeghem (2007) combined simulation and value stream mapping together with existing data base to develop a tool for assessing lean implementation. They introduced a model generator to compare between the current (before lean implementation) and the future (after lean implementation) systems based on improving the value stream. The comparison allows managers to take better decisions on when, where and how to implement lean manufacturing.

From the above literature review, it is observed that most of the work focused on either proposing rules/ recommendations to apply lean manufacturing or investigating different approaches to improve various aspects of lean manufacturing tools. Very few works were presented to understand the lean manufacturing physics. Furthermore, analysing lean manufacturing systems from a dynamic perspective is lacking in the literature. Such dynamic analysis in today's uncertain environment is fundamentally critical to understand and thus better manage lean manufacturing systems. This paper presents a system dynamics approach to study some of the dynamics associated with the application of lean manufacturing system's tools. In particular, the paper focuses on the dynamic impact of implementing production levelling on the performance of lean manufacturing cell. The approach presented is considered a novel initial attempt to explore more and more the dynamics of this excelling manufacturing paradigm.

\section{Dynamic lean cell model}

A system dynamic model for lean manufacturing cell is developed by the author and presented in Figure 2 . The displayed system is composed of a demand component that captures the stochastic nature of the demand and translates it to takt time and pull rate. The production component is modelled as a lean cell with three production centres or stations. The production is controlled by a pull rate that is a function of takt time. A dynamic capacity component is also added to the system to hedge against demand and internal variation. Finally, the backlog of the developed cell is monitored as a performance measure of the lean cell responsiveness to demand. Each of these components and their interactions are discussed in detail in this section.

It is important to note that a continuous-time model is used because it provides an acceptable approximation of the levelled production performance aimed at by lean manufacturing. Both the operations management and system dynamics literature support the use of continuous models for lean manufacturing (e.g. Sethi and Thompson 2000 and Anderson et al. 2005).

\subsection{Model notations}

$B(t) \quad$ Backlog level at time $t$.

$W I P_{i}(t) \quad$ WIP level at time $t$ at station $i$.

$\operatorname{I} P R(t)$ Input production rate.

$P R(t) \quad$ Pull rate. 


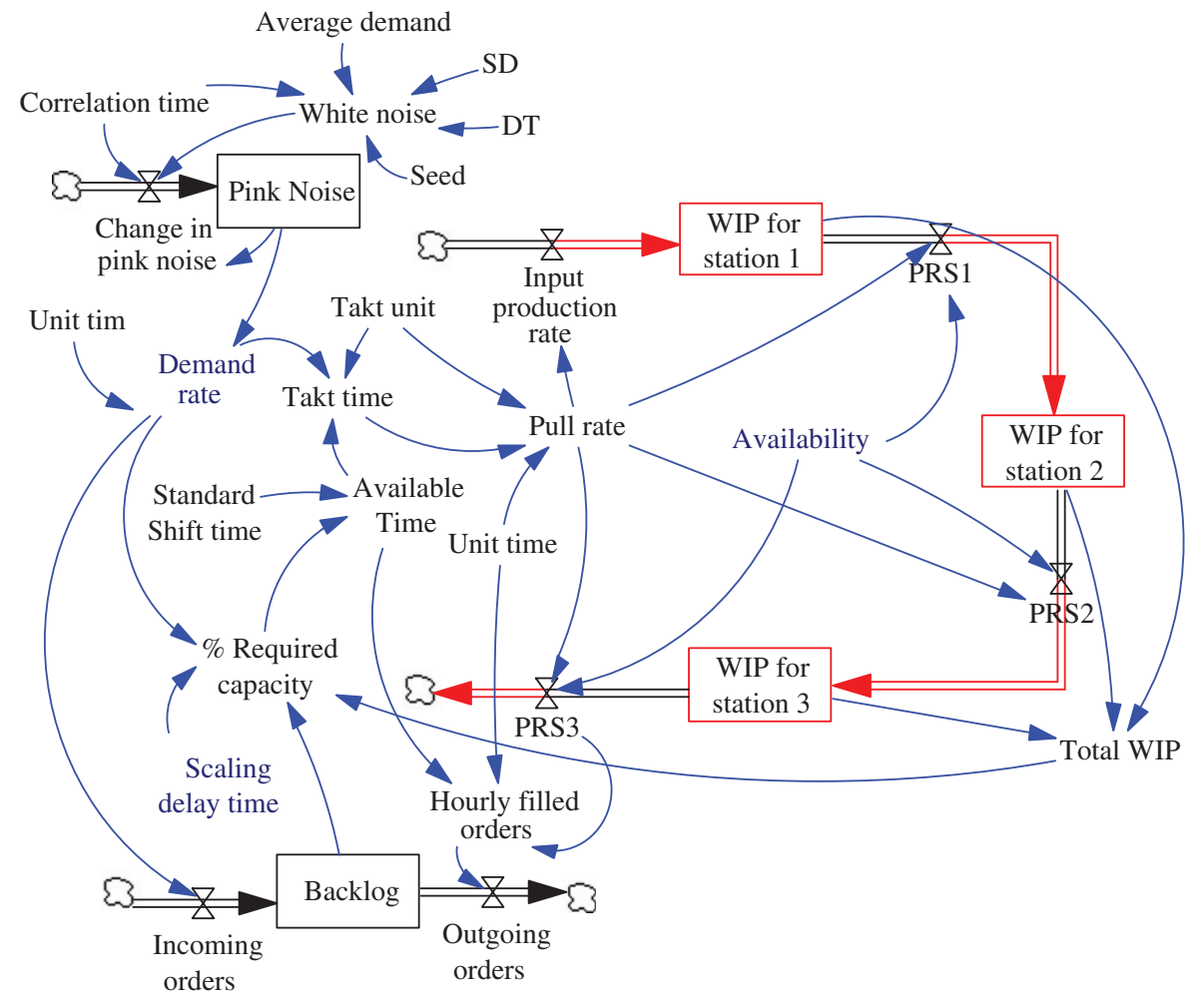

Figure 2. Dynamic lean manufacturing cell.

$\operatorname{PSR}(t)$ Production start rate at time $t$.

$A D(t) \quad A$ verage demand at time $t$.

$C T$ Correlation time. It captures the degree of inertia in the noise process.

$S D$ Standard deviation for the normal demand distribution.

DT Time step.

Seed Seed for randomly generated variates of the stochastic demand data.

Avab System availability.

$I O(t) \quad$ Incoming orders $t$.

$O O(t)$ Outgoing orders $t$. It is the rate of physical product leaving the cell.

$T W I P(t)$ Total WIP of the system at time $t$.

$H F O(t)$ Hourly filled orders at time $t$.

$A T$ Manufacturing available time.

TT Takt time. It is the time that set the production pace.

$\% R C(t) \quad$ Percentage of the required capacity to be scaled at time $t$.

$S D T$ Scalability delay time. Time require to scale the capacity.

SST Standard shift time.

\subsection{Dynamics of a lean manufacturing cell}

\subsubsection{Stochastic market demand}

The market demand is modelled as a stochastic parameter with dependent distribution or pink noise as referred to in the system dynamics literature. While convenient statistically, the independent distribution assumption of demand or white noise does not hold for the real world (Sterman 2000). Modelling demand as white noise simply assumes that the average demand over time is constant with constant variation. To have a better assessment of the impact of demand uncertainty on dynamics of the lean manufacturing cell, it is necessary to model demand forecast as a 

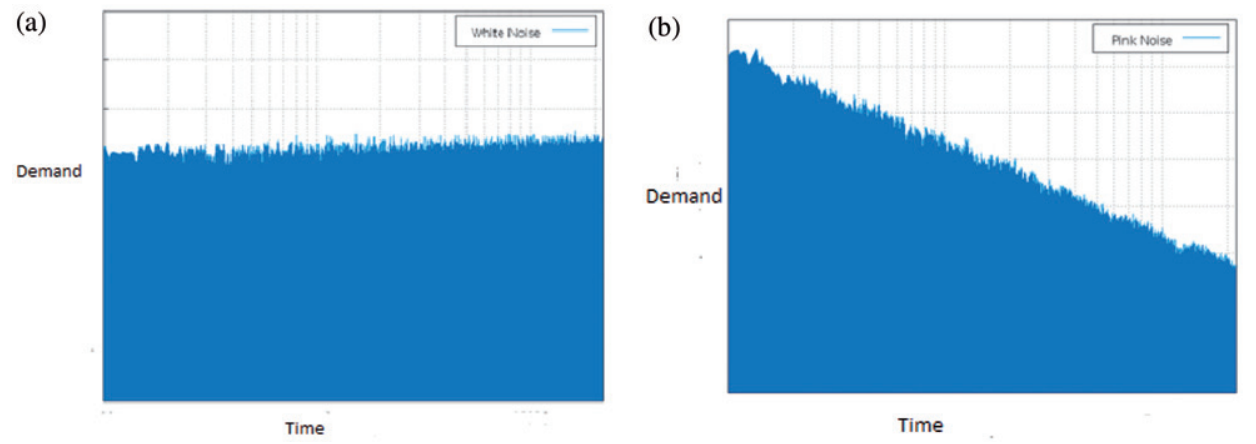

Figure 3. Demand varying (a) as white noise (b) pink noise.

process with memory in which the next value of demand is not dependent on the last but depends on the history of previous forecasts or pink noise. Pink noise, different from white noise, assumes that the variation of the demand is related to all previous demand data in a proportional logarithmic relation. A comparison between white noise and pink noise demand function is shown in Figure 3.

The demand in this model is assumed to have a continuous cumulative normal distribution function. Huh et al. (2006) state that demand should have a continuous distribution because demand is inherently continuous, the variance in demand is often high and finally because continuous demand distribution may generate a more robust capacity plan than finite number of discrete scenarios. Equation (1) formulates the demand as white noise with a normal distribution.

$$
\text { White Noise }(\mathrm{t})=\mathrm{AD}(\mathrm{t})+\left[S D^{2} * \frac{(2-(D T / C T))}{(D T / C T)}\right]^{0.5} * \operatorname{Normal}(0,1, \text { Seed })
$$

Equations (2) and (3) display the values for the demand pink noise and the change in demand pink noise respectively

$$
\begin{gathered}
\text { Pink Noise }(\mathrm{t})=\text { Change in Pink Noise }- \text { Pink Noise }_{0} \\
\text { Change in Pink Noise }=\frac{\text { Pink Noise }(\mathrm{t})-\text { White Noise }(\mathrm{t})}{\text { CT }}
\end{gathered}
$$

Finally the demand rate (DR) is calculated by dividing the change in pink noise by the manufacturing unit time as in Equation (4):

$$
D R(t)=\text { Change in Pink Noise/Unit time }
$$

\subsubsection{Takt time and pull rate}

As mentioned earlier, takt time is how often the manufacturer should produce one part based on the rate of sales to meet customer requirements. Takt time is calculated by dividing the customer demand rate (which is part/hour) into the available working time per day (in hours). Takt time calculation is shown in Equation (5):

$$
T T=\frac{A T}{D R(t)}
$$

The available time is traditionally equal to the standard shift time of the factory times the number of shifts. However, in this paper the author is introducing a new approach to calculate the available time as function of the standard shift time plus additional hours based on scaled capacity if needed. The extra available time introduced by the scaled capacity is due to integrating dynamic capacity policies and technologies to lean manufacturing cells as proposed by the author. Practical examples for such dynamic capacity scaling can be through adding extra working shifts or an additional machine to the cell. The in-depth analysis of such an integrated policy into a lean manufacturing cell is investigated in Section 5. Available time calculation is shown in Equation (6):

$$
A T=S S T(1+\% R C)
$$




\subsubsection{Dynamic capacity modelling}

As just mentioned, dynamic capacity techniques are more common within today's new technologies of changeable, reconfigurable and flexible systems. However, dynamic policies are more challenging than before. In other words, if scaling capacity is feasible, how can we decide on the best amount with which to scale our capacity? In this paper a new hybrid scaling policy is proposed. The hybrid policy is a capacity policy that considers the demand rate, the current system's work in progress (WIP) level and the system's backlog when deciding on the capacity scaling value. This integrated policy is believed to improve a system's overall responsiveness as it accounts for external as well as internal uncertainties. The required capacity (based on the hybrid policy) is shown in Equation (7). It is important to note that a delay time is captured since practically speaking; instantaneous capacity scaling is infeasible in the manufacturing context. The impact of the scalability delay time on the lean cell performance is explored in Section 5.

$$
\% R C=\left[\frac{T W I P+B a c k \log }{S D T}\right] / D R
$$

\subsubsection{Production control}

The WIP level at each station in the lean cell is determined by the difference between the production rate of the current station and the production rate of the next one (Equation (8)).

$$
W \dot{P}_{i}(t)=P R S_{i}(t)-P R S_{i+1}(t)
$$

To demonstrate the dynamics of a lean manufacturing cell, the production rate is set to be equal to a pull rate that was calculated based on takt time. Furthermore, the production rates of all stations in the cell are set to be the same to reflect the lean policy of level production as explained earlier. Finally, the production rates of each station (with the exception of the production input rate) are affected by the availability of the machines. The availability of the machines reflects the internal uncertainties like machines breakdown and other variability sources that would make production capacity not available. For simplicity, it is assumed that all stations inside the lean cell have the same availability. This assumption will be relaxed in further work; however, it does not affect the general analysis conducted in this paper. The previous production dynamics are shown in Equations (9)-(11).

$$
P R(t)=(\mathrm{TT} / \text { Unit Time }) * \text { Takt Unit }
$$

Note that unit time and takt units are parameters that have a value of one and used to keep dimensional (units) balance. Also in Equation (10), the input production rate is equal to the pull rate (no over capacity is considered) as this reflects the traditional practice of lean pull systems.

$$
\begin{gathered}
I P R(t)=P R(t) \\
P R S_{i}(t)=P R(t) * A v a b .
\end{gathered}
$$

\subsubsection{Backlog calculation}

The backlog level is used in this model as an indicator of the responsiveness level of the manufacturing cell as well as reflecting an important waste that lean systems would like to battle which is overproduction. It is calculated as the difference between the input order rate (which is assumed to be exactly equal to the hourly demand rate as in Equation (4)) and the outgoing order rate. The outgoing order rate is function in hourly filled order which is based on both the production rate of the lean cell (controlled by the last station's rate) as well as the available time. Backlog calculations are expressed in Equations (12)-(15).

$$
\begin{gathered}
\dot{B(t)}=O O(t)-I O(t) \\
I O(t)=D R(t)
\end{gathered}
$$


Table 1. Values of the base case parameters.

\begin{tabular}{|c|c|c|}
\hline Data & Value & Comments \\
\hline \multicolumn{3}{|l|}{ Market information } \\
\hline Average demand (AD) & 80 parts/hour & This is the value of the average customer order. \\
\hline Standard deviation (SD) & \pm 8 parts/hour & This reflects marketing fluctuation of $\pm 10 \%$. \\
\hline Correlation time $(\mathrm{CT})$ & 4 hours & $\begin{array}{l}\text { This means that each demand forecast depend } \\
\text { on the actual data of the preceding } 4 \text { hours. }\end{array}$ \\
\hline Time step (DT) & 0.125 hour & \\
\hline Seed & 9 & $\begin{array}{l}\text { Used to generate random variates for the } \\
\text { normally distributed demand data. }\end{array}$ \\
\hline \multicolumn{3}{|l|}{ Production information } \\
\hline Machine availability (avab.) & Random uniform $(0.95,1,0)$ & $\begin{array}{l}\text { The availability of the machines at each of the } \\
\text { cell's stations varies randomly between } 0.95 \\
\text { and } 1 \text { with a uniform distribution. This } \\
\text { means that the machines are up } 95 \%-100 \% \\
\text { of the time. }\end{array}$ \\
\hline Standard shift time (SST) & 8 hours & $\begin{array}{l}\text { It is assumed that the facility works one } 8 \\
\text { hours shift excluding lunch and breaks. }\end{array}$ \\
\hline Scalability delay time (SDT) & 2 hours & $\begin{array}{l}\text { This is the time required to decide, implement } \\
\text { and tune up the system with scaled capacity. }\end{array}$ \\
\hline Unit time & 1 hour & Used to maintain units balance in the model. \\
\hline Takt unit & 1 part/hour & Used to maintain units balance in the model. \\
\hline
\end{tabular}

$$
\begin{gathered}
O \dot{O}(t)=H F O(t) \\
H F O(t)=\operatorname{PRS} 3(\mathrm{t}) * \mathrm{AT} * \text { Unit Time }
\end{gathered}
$$

\section{Quantifying the impact of uncertainty on lean cell}

In this section, the developed lean manufacturing cell is analysed. The analysis explores the impact of both demand uncertainty as well as the machine availability on the lean cell performance. The performance metric used in the analysis is the backlog as it reflects the cell's responsiveness to demand as well as overproduction waste of the cell. The analysis will also include a comparison between the lean manufacturing cell with a dynamic capacity and the same cell with static capacity using the same performance metric.

The chosen parameters' values for the base case are shown in Table 1. The selected values for the different time parameters are based mainly on the practical experience of the author with lean automotive suppliers. Altering the values of these parameters and examining the impact of each one of them can lead to some insights; however, such analysis is beyond the scope of this paper. The model is initialised at equilibrium (i.e. the initial values of the WIP and backlog levels were set to zero since the conventional practice in a lean manufacturing assumes zero inventory) and simulated for 200 hours (to account for transient and stable behaviour).

\subsection{Is the modelled cell lean?}

Before proceeding with the analysis of the considered manufacturing cell's performance under uncertainty, some simulation runs were conducted to check whether the modelled cell is really lean or not. Among the many characteristics of a lean cell stand low WIP level and levelled production as the most distinct characteristics of a lean manufacturing cell. Figure 4 plots the WIP level for the three stations in the considered cell. It is obvious that the WIP level is at a very minimal value at station one while it is zero at stations two and three. This is typical for lean systems as WIP decreases downstream due to the adoption of pull production policy.

Figure 5 shows the production level at the three stations of the cell. The production at all stations is levelled around the rate of 1 part $/ 0.1$ hour. The minor fluctuation observed is due to producing at takt time. As mentioned 


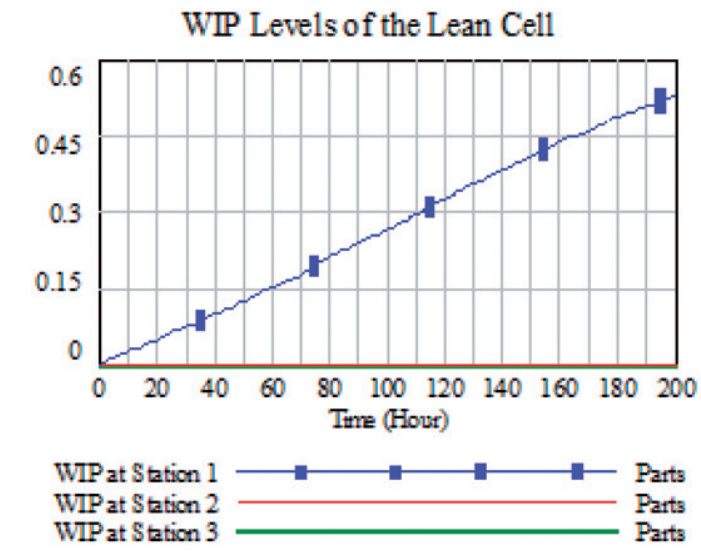

Figure 4. WIP level at the three stations of the lean cell.
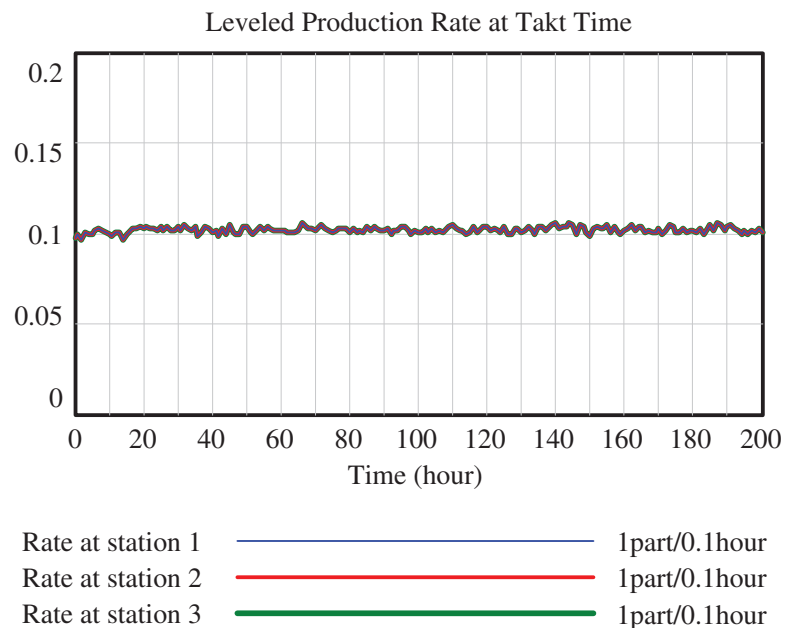

Figure 5. Production rate level at the three stations of the lean cell.

(b) $\quad$ Graph for \% Required Capacity

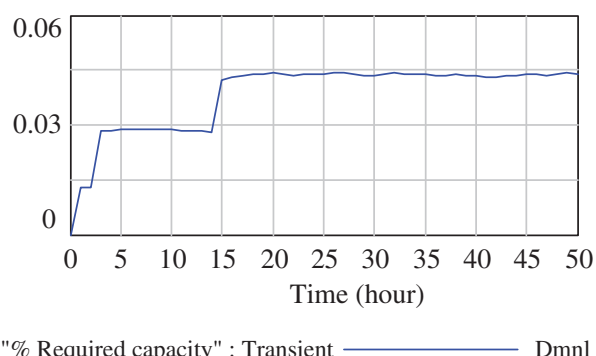

Figure 6. Transient behaviour of (a) backlog level, (b) required capacity.

earlier takt time is based on the demand rate, and the fluctuation in the considered demand is reflected in the production rate but in a much smoother profile.

Based on Figures 4 and 5 one can judge the performance of the modelled manufacturing cell as a lean performance from the WIP level and levelled production perspectives. However, it should be mentioned that such lean performance is also highly related to the adoption of the dynamic capacity policy integrated within the model. The dynamic capacity policy contributes to the cell leanness through considering both the total WIP level and the accumulated backlog when deciding to scale up the cell available hours to respond to demand. Without a dynamic policy and with a fluctuating demand scenario, manufacturing cells would witness an increase in both WIP and backlog levels. The effect of the dynamic capacity policy is demonstrated in the following comparison.

\subsection{Insight into the transient behaviour of the dynamic lean cell}

Dynamic analysis of any system requires capturing both the transient and the stable behaviour of the dynamic system upon excitation. In this section, a brief insight on the transient behaviour of the dynamic lean cell when excited by the captured demand is presented. The rest of the analysis will focus on the performance after the system maintains stability to highlight the impact of production levelling lean polices and system settings on the lean cell general performance.

Figure 6 (a) and (b) shows the transient behaviour of the backlog (a) and the percentage of the scaled capacity (b). From the figure it is shown that when the system is triggered by the demand, it required some time to reach the stable backlog and capacity scaling levels. In addition, both levels were rising constantly in the first 4 hours then 


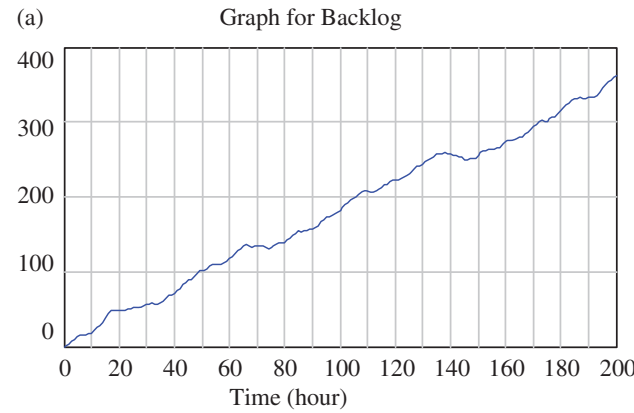

Backlog : Stochastic Demand-Non Dynamic — Parts

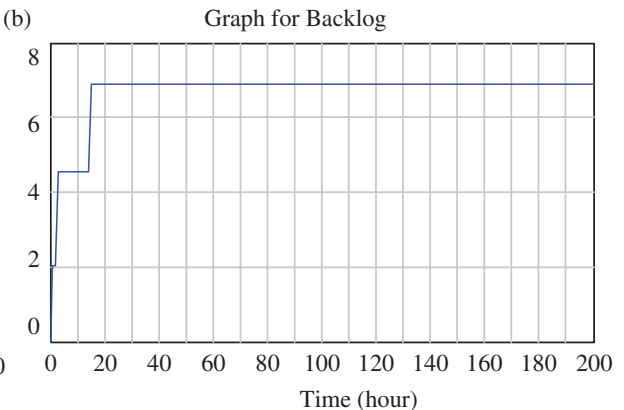

Backlog : Stochastic Demand-Dynamic $\longrightarrow$ Parts

Figure 7. (a) Backlog level in the lean cell without dynamic capacity. (b) Backlog level in the lean cell with dynamic capacity.

were stable for about another 10 hours and then they overshoot to their stable levels in 1 hour (from 14 to 15). The reasons behind such behaviour are as follows.

The backlog was initiated at zero level and thus it start to rise reflecting the accumulated unmet demand (due to variability in availability and demand) till the dynamic capacity system managed to compensate for the backlog accumulation as will be explained later. This also explains the rising behaviour of the percentage of the required capacity. The transient profile demonstrated in Figure 6 is due to having a delay in the causal link of the negative feedback loop of the dynamic capacity scalability system of the lean cell. It took the capacity system 3 hours to catch up with the discrepancy in the backlog as well as clearing accumulated WIP and then the system required another hour later on to reach a stable performance were no more backlog or WIP accumulated.

\subsection{Impact of dynamic capacity on lean cell responsiveness}

Figure 7 (a) and (b) compare the backlog level of the modelled cell without a dynamic capacity and with a dynamic capacity policy respectively. The continuous accumulation of backlog in Figure 7 (a) while the low and stable level of backlog in Figure 7 (b) prove the importance of dynamic capacity policies in increasing responsiveness level and minimising overproduction as dictated by the lean manufacturing principles.

A fundamental approach for lean manufacturing systems to have a smooth and levelled production, while still being responsive, is through dynamic capacity systems that hedge against various uncertainties in the manufacturing environment. Although lean principles try to manage many of these uncertainties through various approaches, such as visual control techniques and productive maintenance, the reality of manufacturing practice, however, shows that at least a minimal number of these uncertainties is inevitable. Having said that, in order for these dynamic capacity systems to absorb manufacturing uncertainties, they should adopt hybrid scaling policies that compensate for various internal and external disturbances as discussed earlier.

\subsection{Impact of uncertainty on lean cell responsiveness}

In this section we refer to uncertainty as external uncertainty demonstrated by demand stochasticity and internal uncertainty represented by machine availability variation. Demand uncertainty is what characterises today's global competitive environment. In Figure 8 it is shown that the backlog level under stochastic demand pattern for the modelled lean manufacturing cell is almost doubled when compared with the deterministic demand scenario. This puts an important challenge in front of lean manufacturing systems to maintain their objective of high responsiveness level. Although in both cases the backlog level is relatively small (thanks to the dynamic capacity contribution); however, much effort is required to capture, manage and reduce demand uncertainty upstream of the lean manufacturing system.

To further demonstrate the impact of uncertainty, the effect of machine availability variation together with demand variation on the lean manufacturing cell backlog is explored. Figure 9 compares what we can call the ideal lean manufacturing system performance with the current performance of the modelled lean cell under the considered operational scenario. It is clear from the figure that with an ideal lean manufacturing environment where demand is 


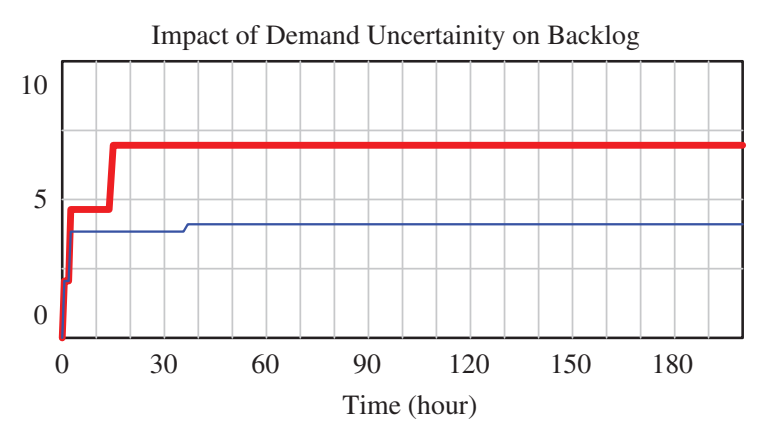

Backlog-Det. Demand parts

Backlog-Stoch. Demand parts

Figure 8. Impact of demand uncertainty on lean manufacturing cell responsiveness.

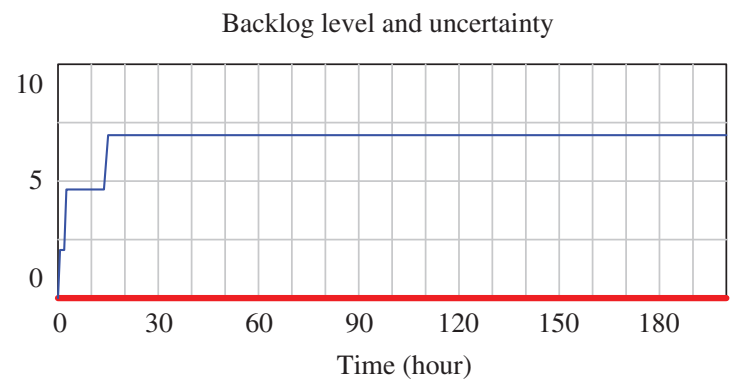

$\begin{array}{ll}\text { Uncertainty captured } & \text { parts } \\ \text { Uncertainty not captured } & \text { parts }\end{array}$

Figure 9. Backlog level of the lean manufacturing cell with full availability and deterministic demand vs. variable availability and demand.

fully captured and smoothed and the machines are perfectly available, manufacturing systems can be fully responsive to the customer requirements in the most efficient manner (no over production waste).

The difference between the two scenarios plotted in Figure 9 can act as a roadmap for continuous improvements plans (or kaisen with lean terminologies). Although the dynamic capacity integration managed to push the lean manufacturing cell towards an acceptable lean performance through accommodating for many of the manufacturing variability, it is obvious that ideal lean performance is achieved through rigorous effort to manage the uncertainty dynamics from its root causes. As simple as this can sound, it is known to manufacturing practitioners that this is the biggest challenge they have to face in today's global and competitive environment.

\subsection{Impact of scaling delay time on lean cell performance}

The final analysis will examine the impact of the scaling delay time (SDT) on the performance of the lean cell in terms of responsiveness and cost. The scaling delay time usually reflects time required to decide on the new required capacity level, the type of the capacity to be scaled and the implementation of the new capacity level (this includes installation and ramp up time). The type of capacity has a significant impact on the delay time. For example, soft capacity scaling decisions (e.g. using extended hours or adding extra shifts) will have less scaling delay time than hard capacity scaling decisions (e.g. reconfiguring a machine by adding extra spindle or even adding an extra machine to the cell).

Figure 10 shows the impact of scalability delay time on the backlog level of the modelled lean cell. From the figure it is clear that as the delay time increases, the backlog level also increases. This direct relation between scalability delay time and backlog level highlights a key point to increase the responsiveness level of lean manufacturing systems. With the adoption of dynamic capacity systems in lean manufacturing, various efforts and techniques should be allocated to reduce the scalability delay time associated with the dynamic capacity. Lean techniques like SMED (single minute exchange of dies), which is implemented to maintain a quick change-over time to cope with a variety of products, are recommended in this case to reduce the capacity scalability delay time.

Figure 11 highlights the relation between scalability delay time and the percentage of the required capacity. This relation can be used to determine the impact of scalability delay time on some of the costs associated with dynamic capacity systems. It is obvious that the higher the required capacity to be scaled, the higher will be the cost. From the figure, there is an inverse relation between scalability delay time and the extra capacity that will be required to meet the demand while levelling production. From a practical perspective, this is true since the more time the capacity planner has the cheaper the scaling options would be (for example, the same worker working extended hours is cheaper than hiring extra workers). However, this observation will leave the capacity planner in lean manufacturing systems with a trade-off decision to make where she/he should strive to balance between high responsiveness level (lower backlog levels) and acceptable cost for capacity scalability. Both targets are competing when it comes to decide on the scalability delay time. 

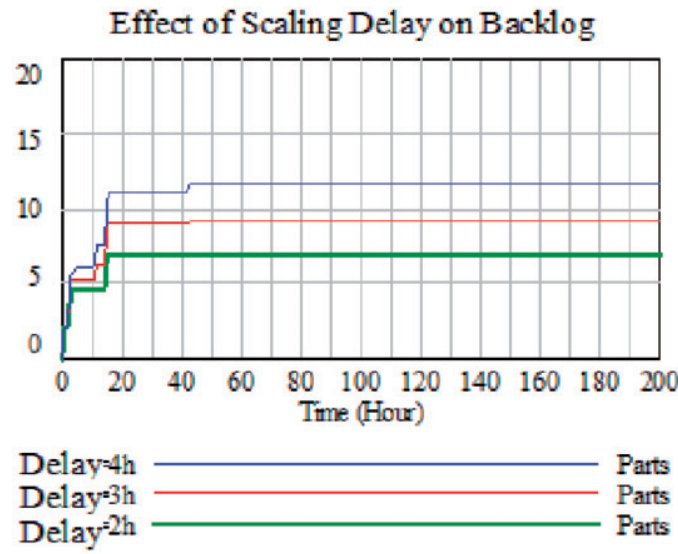

Figure 10. Effect of scaling delay time on the backlog level of the lean cell.
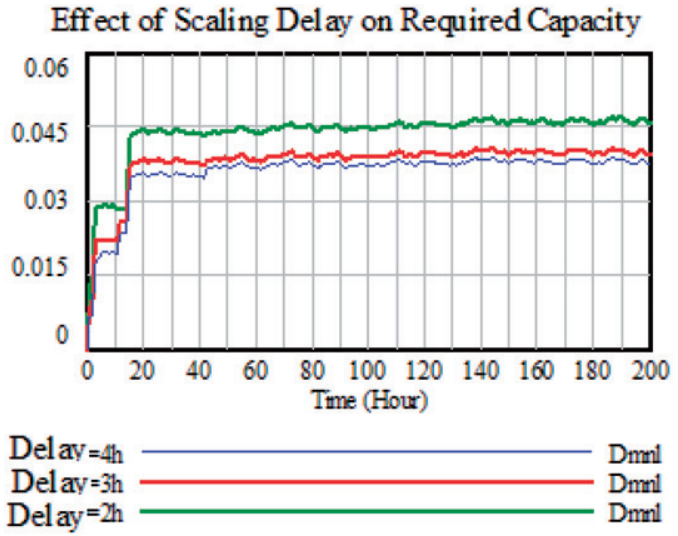

Figure 11. Effect of scaling delay time on the required percentage of extra capacity for the lean cell (Dmnl: dimensionless).

\section{Summary and recommendations}

The need for dynamic analysis of lean manufacturing systems is becoming more evident with the widespread and continuous calls to implement lean principles and tools in the suffering manufacturing sector. This paper presented a system dynamics approach to explore some of the dynamics associated with the lean principle of production levelling. The analysis focused on a simple lean cell that produces using pull policies which are function in the takt time. The analysis examined the impact of uncertainty caused by demand variation and system's availability on the performance of the lean cell. Various dynamic issues were demonstrated through different scenarios and summarised as follows:

- Among other factors contributing to the successful implementation of levelled production in a lean cell is the existence of a dynamic capacity policy. The dynamic capacity absorbs the impact of demand variation as well as internal uncertainty resulting from machines' availability.

- Demand uncertainty was shown to reduce lean cell responsiveness level. Traditional lean manufacturing principles have an underlying assumption that the demand rate provided to the manufacturing system is somehow stable. Such assumption requires further investigations as results in this study showed that the backlog of a lean cell under stochastic demand is almost double its value when the same cell is compared under deterministic or stable demand.

- There is a difference between lean manufacturing cell and cells implementing lean techniques. This was demonstrated through exploring the impact of machines availability on the cell's backlog and responsiveness level. With uncertain machine availability, although lean production principles are employed (pull systems and level production), the cell lean performance was adversely affected. Lean systems are supposed to have ideal machine availability prior to full implementation of lean production principles. In addition, setting production exactly equal to demand through a pull system (as the classical pull practice) without recognising the need to have a small over capacity will magnify the impact of variability on WIP and backlog levels.

- Improving responsiveness of the lean cell and reducing the costs of dynamic capacity are both competing objectives when it comes to deciding on the acceptable capacity scalability delay time. In addition the delay time showed an important role in the stability of the performance when it comes to the transient behaviour of dynamic capacity systems in lean cells.

To help lean practitioners have a smooth lean implementation and specifically level production, the author outlines the following recommendations:

- Implementation of dynamic and scalable capacity systems within lean manufacturing cells. The suggested dynamic capacity systems algorithm in this work is to adopt hybrid capacity scalability policies to manage production fluctuation. Hybrid policies should account for demand, WIP level and backlog accumulated when deciding on the scalability level. 
- The dynamic nature of demand and lean production will require more investigation of the required dynamic control policies. In the light of this paper, management should consider the impact of sudden or very quick as well as frequent change of capacity on system stability and cost versus quick responsiveness to demand. Results showed that an acceptable level of backlog and WIP can be tolerated for better stability and less production cost.

- More effort is required to better manage and control uncertainty within the lean manufacturing environment. Lean manufacturing systems should work upstream to smooth demand fluctuation in order for level production operation to be fully successful. In addition, working on improving machine availability would increase the leanness of manufacturing systems as well as the smoothness of one piece flow production. Lean systems should efficiently utilise available lean techniques that can help to raise machine availability like productive maintenance, visual control and kaisen.

- Having a clear management strategy on how to balance between responsiveness and capacity scalability costs to maintain levelled production. The strategy should reflect market objectives as well as lean principles.

- Optimal lean implementation depends on using effective lean mechanisms within the boundaries of system constraints and strategic goals.

Future work is still required to explore more dynamic issues in lean manufacturing. For example, the impacts of other complicated pull policies on the lean cell performance. In addition, the presented dynamic analysis should be extended to multiple stage production (i.e. many cells connected together). Furthermore, parametric and sensitivity studies for the various parameters involved in the modelling approach would reveal different understandings about the role of these parameters in lean systems. These understandings will eventually help to better manage lean manufacturing systems. Finally the transient response of the lean dynamic cell behaviour also requires more investigations. In conclusion, as much as lean principles smooth the manufacturing system and make it more responsive, as much dynamics are generated during this process which eventually need to be better studied and understood.

\section{References}

Anderson, E., Morrice, D., and Lundeen, G., 2005. The 'physics' of capacity and backlog management in service and custom manufacturing supply chains. System Dynamics Review, 22 (3), 217-247.

Askin, R.G. and Krishnan, S., 2009. Defining inventory control points in multi-product stochastic pull systems. International Journal of Production Economics, 120 (2), 418-429.

Black, J.T., 2007. Design rules for implementing the Toyota production systems. International Journal of Production Research, 45 (16), 3639-3664.

Carlson, J.G. and Yao, A.C., 1992. Mixed-model assembly simulation. International Journal of Production Economics, 26 (1), $161-167$.

Cochran, D.S., et al., 2000. The application of axiomatic design and lean management principles in the scope of production system segmentation. International Journal of Production Research, 38 (6), 1377-1396.

Detty, R. and Yingling, J., 2000. Quantifying benefits of conversion to lean manufacturing with discrete event simulation: a case study. International Journal of Production Research, 38 (2), 429-445.

Galbraith, L. and Standridge, C.R., 1994. Analysis in manufacturing systems simulation: a case study. Simulation, 63 (6), 368-375.

Graban, M., 2008. Lean hospitals: Improving quality, patient safety, and employee satisfaction. New York: Productivity Press.

Hall, R.W., 1983. Zero inventories. Home Wood, Illinois: Dow Jones-Irwin.

Hogg, D., 2009. Putting on new glasses for the new world of manufacturing. Manufacturing Engineering, SME, 143 (5), 17-20.

Hu, G., et al., 2008. A multi-objective model for project portfolio selection to implement lean and Six Sigma concepts. International Journal of Production Research, 46 (23), 6611-6625.

Huh, W.T., Roundy, R.O., and Cakanyildirim, M., 2006. A general strategic capacity planning model under demand uncertainty. Naval Research Logistics, 53 (2), 137-150.

Lian, Y. and Van Landeghem, H., 2007. Analysing the effects of Lean manufacturing using a value stream mapping-based simulation generator. International Journal of Production Research, 45 (13), 3037-3058.

Middleton, P., 2001. Lean software development: Two case studies. Software Quality Journal, 9 (4), $627-639$.

Nahmens, I., 2007. Mass customisation strategies and their relationship to lean production in the homebuilding industry. Thesis (PhD). University of Central Florida. 
Pavnaskar, S.J., Gershenson, J.K., and Jambekar, A.B., 2003. Classification scheme for lean manufacturing tools. International Journal of Production Research, 41 (13), 3075-3090.

Pay, R., 2008. Everybody's jumping on the lean bandwagon, but many are being taken for a ride. Industry Week, May, 21-23. Rother, M. and Shook, J., 2003. Learning to see. Cambridge, MA, USA: The Lean Enterprise Institute.

Sampson, M., 2004. Nonprofit, payload process improvement through lean management. Thesis (PhD). University of Colorado at Boulder.

Sanchz, L. and Nagi, R., 2001. A review of agile manufacturing system. International Journal of Production Research, 39 (16), 3561-3600.

Savasar, M. and Al-Jawini, A., 1995. Simulation analysis of just in time production systems. International Journal of Production Economics, 42 (1), 67-78.

Schonberger, R.J., 1982. Japanese manufacturing techniques: Nine hidden lessons in simplicity. New York: The Free Press.

Sethi, S.P. and Thompson, G.L., 2000. Optimal control theory: Applications to management science and economics. Boston, MA: Kluwer.

Shah, R. and Ward, P., 2007. Defining and developing of lean production. Journal of Operation Management, 25 (4), $785-805$.

Shingo, S., 1989. A study of the Toyota Production System from an industrial engineering viewpoint. Portland, OR: Productivity Press.

Sterman, J., 2000. Modeling complex world. New York: McGraw-Hill.

Tischler, L., 2006. Bringing lean to the office. Quality Progress, 39 (7), 34-42.

Tracy, D.L. and Knight, J.E., 2008. Lean operations management: Identifying and bridging the gap between theory and practice. Journal of American Academy of Business, 12 (2), 104-112.

Welgama, P.S. and Mills, R.G.J., 1995. Use of simulation in the design of a JIT system. International Journal of Operations and Production Management, 15 (3), 245-260.

Womack, J. and Jones, D., 2003. Lean thinking. New York: Free Press. 